\title{
Remote Laboratory in Control Process during COVID-19 Pandemic Situation
}

https://doi.org/10.3991/ijoe.v17i10.24693

\author{
Hajar Baghdadi $\left.{ }^{1}{ }^{(}\right)$, Mohamed Massour El Aoud ${ }^{2}$, Ismail Lagrat ${ }^{3}$, Karim Rhofir ${ }^{2}$, \\ Noureddine Elbarbri ${ }^{2}$, Mohamed Lamhamdi ${ }^{1}$ \\ ${ }^{1}$ Hassan 1st University, Settat, Morocco \\ ${ }^{2}$ Sultan Moulay Slimane University, BeniMellal, Morocco \\ ${ }^{3}$ Ibn Tofail University, Kenitra, Morocco \\ h. baghdadi@uhp.ac.ma
}

\begin{abstract}
Today we are witnessing an unprecedented pandemic called the "COVID-19 pandemic" which has created the greatest disruption to education systems in human history. It has caused the closure of schools, institutions and other learning spaces, causing profound changes in all aspects of our lives. Policies of social distancing and restriction of movement have significantly disrupted traditional educational practices. Faced with this problem, it is time to innovate and implement an alternative education system and assessment strategies. The work presented in this paper responds to this problem and aims to provide a practical work environment which allows engineers to complete their basic training with the use, control and handling of measuring instruments often used in the real world. This environment will therefore be accessible online and makes it possible to control the process.
\end{abstract}

Keywords-remote laboratories, distance learning, engineering education, distance practical work

\section{Introduction}

The global outbreak of the COVID-19 pandemic, first identified in December 2019 in Wuhan, China, has spread around the world, affecting nearly every country and continent. Governments of countries around the world have warned the public to be vigilant. Public care strategies have included closing establishments as well as certain instructions such as washing hands, wearing face masks, physical distancing and avoiding mass gatherings. Lock-in and home-keeping strategies have been put in place as a necessary action to flatten the curve and control disease transmission [1].

The pandemic has severely affected the education system worldwide. More than 100 countries have implemented the shutdown nationally, affecting approximately $90 \%$ of the world's student population and putting their future educational rights at threat. The closure of the schools has not only affected the students, their educators and their families. But it also has important economic and societal impacts. Hence, there is a need for every division of education at regional and national levels to develop safeguard 
measures and mechanisms to create flexible and innovative programs, accessible at anytime and anywhere.

Indeed, governments have taken various measures to deal with the virus outbreak. In order to stop the transmission of the virus, schools and universities have established different ways to communicate with students via the Internet. Different countries around the world have presented a variety of solutions during the pandemic to continue the progression of education, including video conferences and online channels, support for online libraries, television broadcasts, resources.

In Morocco, since mid-March 2020, around 10 million students have been taken out of school because of the pandemic [2].To control the transmission of the virus, a number of decisions have been announced, including confinement, state of health emergency and the closure of schools and universities since 16 March. Therefore, in the twelve regions of the country, distance learning has been adopted to ensure and complement the course program. Regarding higher education, each university has its own platform. Today, university students have an institutional account that allows them to access these platforms, which are a source of information exchange and document sharing. Students are now familiar with such platforms such as Moodle [3] or Google Classroom [4] or Teams [5]. Additionally, the ministry has set up public television channels to broadcast courses for students with difficult access to the Internet [6].

However, for practical works, most of Moroccan universities are still obliged to hold presential sessions in laboratories. For that, we propose to adopt remote laboratories providing students with the necessary experience to help them understand the theories discussed in lecture.

The paper is organized as follows. The next section responds to the question why, when and how can Remote Laboratories be created to boost the transition from face-toface education to remote education. Section 3, describe the remote environment architecture for our proposition, and section 4 presents the software and hardware requirements for the remote laboratory process. Finally, section 5 provides a discussion on the goals achieved and the points of further research.

\section{Remote lab becomes a necessity}

Learning in many areas of engineering requires laboratory work to supply practical knowledge and skills to students and to illustrate different real-life processes. Many laboratories have specific process trainers for training in the field of process engineering and control. However, these labs do not have remotely controlled process models and so the student cannot take advantage of them during online learning. As we know, the Internet offers great potential for high-level control of process installations. Therefore, this e-learning will guarantee hard knowledge and skills to engineering students (especially in the field of industrial engineering, process engineering and control engineering), and thus helps them handle specific industrial process control architectures, mechanisms and algorithms. The knowledge and experience built up by process trainers (controlled remotely via the Internet) could be easily applied to real problems [7]. 
Many programs are now incorporating remote (and/or virtual) laboratories into their teaching to save money, extend limited resources or share equipment with another institution. It is likely that few, if any, engineering programs implement remote labs for pedagogical reasons, so the resulting benefits to learning may be a pleasant surprise. Depending on how the labs are deployed, these benefits are likely to include increased student access to equipment, greater flexibility in scheduling labs, a wider range of possible assignments or activities and greater opportunities for collaboration between students[6], [8]-[14].

Increasing the amount of time that students have access to laboratory equipment may result in an increase in the amount of time spent on tasks per student. Longer access may also refer to the types of equipment on which students may work. Either of these scenarios is likely to result in more and/or more diverse learning. When labs are accessed online, students can be engaged in learning at any time and from any location where they have Internet access, rather than waiting for campus buildings to be open and for staff members to be available to carry out their practical activities. This increased access allows for activities that may last longer than a typical class meeting or for multi-part assignments that involve students using the equipment for numerous short periods of time over the course of a week or more, both of which creates logistical challenges in a hands-on environment. Furthermore, the opportunities for student collaboration can be enhanced when laboratories are accessible online, removing the location and time constraints imposed by traditional work groups. For the future engineer, working in a team with members spread across the country (or the world) may be the norm, and giving students the opportunity to practice skills useful in this work environment (e.g., communication and teamwork) can give them a head start [15][16].

Remote laboratories are flexible and decentralized environments that allow learners to perform real experiments with real instruments via the web and also to test and correct errors by analyzing real data [17]. The developments of remote laboratories have motivations and advantages presented in Figure 1.

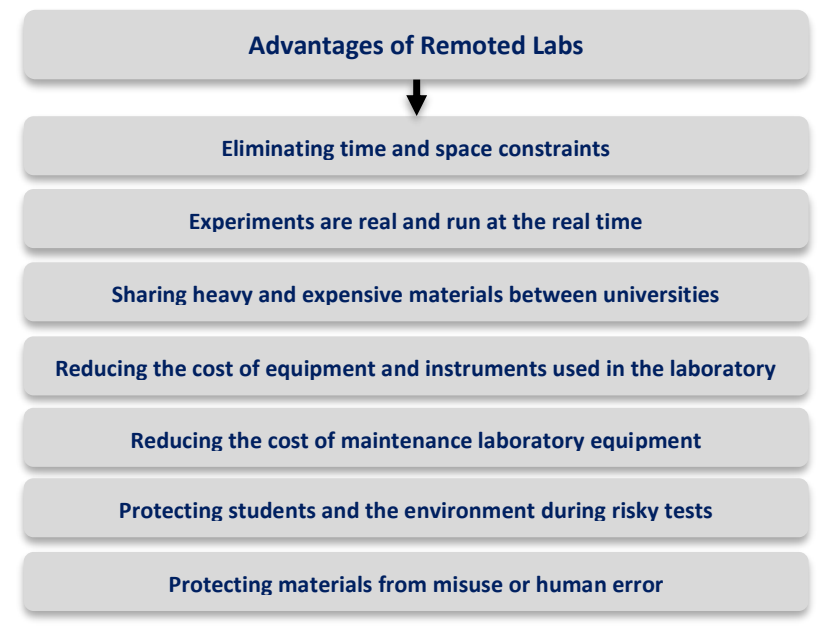

Fig. 1. Advantages of remote labs 
In this architecture used by [17]-[20], learners will be able to send commands themselves through the web browser. These commands will be sent by the user to the practical work server, and then run the experiment in the real device. The practice server will collect the results and send them to the user's interface. The existence of a webcam lab allows the learners to have a clear idea of the different aspects of the real experiment as if it were taking place in a conventional lab to conduct the experiment and visualize it in real time.

A virtual engineering and science laboratory [21] at Johns Hopkins University allows engineering and science laboratory projects to be simulated on a remote computer. With Internet access, it offers students "virtual labs" to work on their projects via the World Wide Web. The experiments are a Java-based system, which demands that the students access them using a web browser. Students firstly download a JAVA applet which serves as their graphical interface GUI and also establishes communication between the client and the server. They then build their experimental system using the GUI objects; after defining the working conditions of the experiment and submitting it, the simulated experimental results are returned to them from the server.

Carnegie Mellon's virtual laboratory [22] allows students to perform real experiments at any time and from any location by accessing laboratory instruments remotely via computer. The instrumentation available in the central laboratory is composed of a function generator, a digital oscilloscope and a digital multimeter. The instruments are operated by HP-VEE software running under Windows on a personal computer. Remote control of the computer is possible with Timbuktu software, and PC/TCP software enables connection to the Internet. Live video is available through a Connectix camera and QuickPICT software. This technology greatly improves the flexibility of laboratory teaching and initiates students to remote experimentation.

\section{Remote environment architecture}

The virtual laboratory is a virtual experimental environment in which users can operate a variety of graphical units, each representing an experimental object, to perform virtual or real experiments remotely via the internet using a local mouse or keyboard.

\subsection{Global architecture}

The global architecture consists of internet access from a computer, smartphone, laptop computer, or tablet to a remote environment for monitoring and taking measurements.

The following architecture gives an overall idea of the remote environment described in Figure 2. 


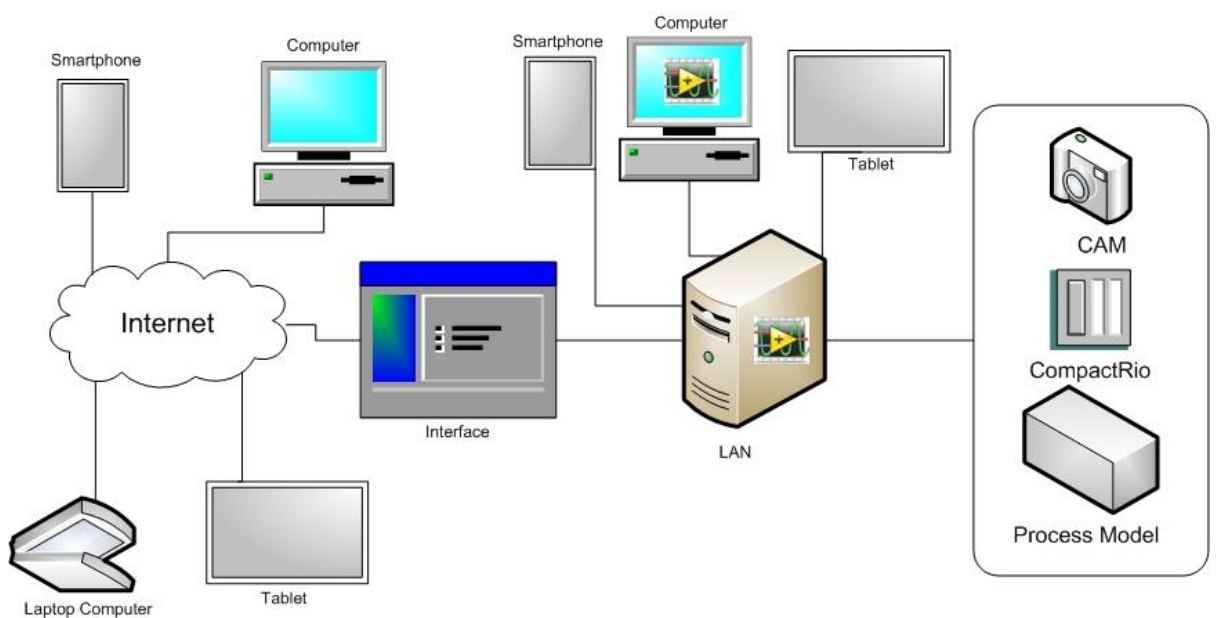

Fig. 2. Remote laboratory architecture

We use the web server architecture to access the laboratory.

\subsection{Server architecture}

The remote server consists of three components (See Figure 3).

- A web server for web access.

- A database server for the management of the students.

- An application server containing the LabView interface with all the practical work documents.

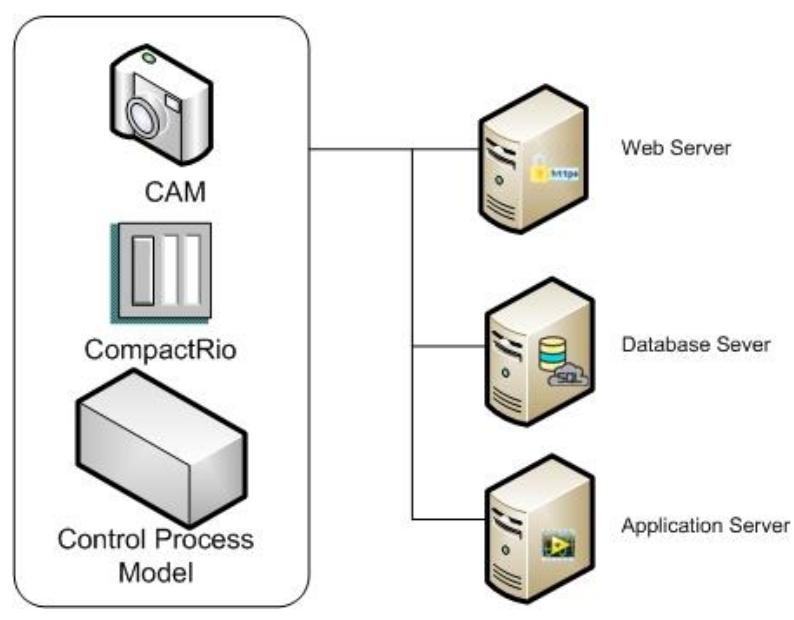

Fig. 3. Server architecture 


\subsection{Control process architecture}

Control process architecture is composed of a camera for live visualization of the evolution of the control processes, a CompactRIO which in turn is composed of a chassis, Ni-cRIO 9025, and five modules, and a pedagogical model for control and regulation process similar to the industrial one.

\section{$4 \quad$ Requirements for remote laboratory}

On the presented section are available all materials and software necessary for the implementation of one of the labs:

- Materials

- Process Trainer PT001

- CompactRIO Real-Time Controller: NI cRIO-9025 (See Red part of Figure 5)

- Chassis : NI cRIO-9118 (See Figure 5)

- C Series Modules (cRIO: NI-9219, NI-9203, NI-9263, NI-9474, NI-9422) (See Green part of Figure 5)

- PC with monitor

- Webserver, Database Server, and Application Server

- Webcam

- Control Process Model (See Figure 4)

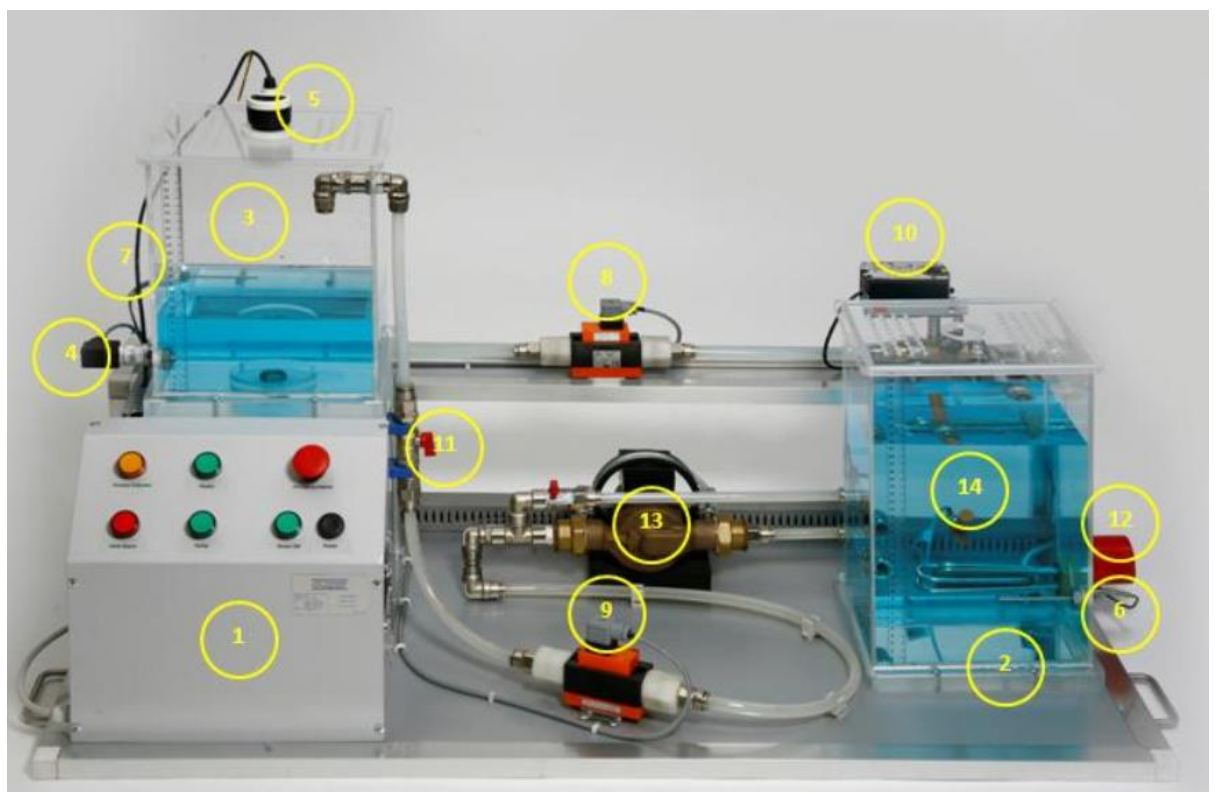

Fig. 4. Control process model 
Table 1. Components laboratory of control process

\begin{tabular}{|l|l|l|l|}
\hline 1 & Electric Control Box & 8 & Flow Meter (Upper) \\
\hline 2 & Tank 1 & 9 & Flower Meter (Lower) \\
\hline 3 & Tank 2 & 10 & Electric Flow Control Valve \\
\hline 4 & Pressure Sensor & 11 & Manual Flow Control Valve \\
\hline 5 & Ultrasonic Level Meter & 12 & Heater \\
\hline 6 & Thermocouple Tank 1 & 13 & Pump \\
\hline 7 & Thermocouple Tank 2 & 14 & Level Switch \\
\hline
\end{tabular}

Such a process is controllable by a PLC, an FPGA embedded board, or a microcontroller board. In this virtual laboratory work, we have chosen to use a CompactRIO because it communicates over standard Ethernet using TCP/IP. The CompactRIO is a combination of a real-time controller, reconfigurable I/O modules (RIOs), an FPGA module and an Ethernet extension chassis [23].

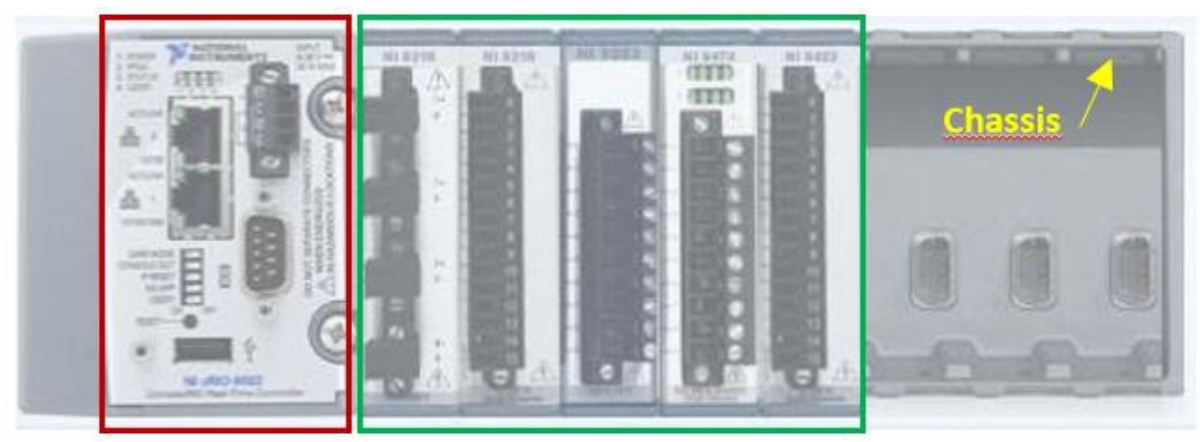

Fig. 5. NI CompactRIO device

\section{- Software}

- LabView and RunTime for the interface

- DataBase Management System (SQL) for managing the students access

The following figure shows the assembly of our process control model: 


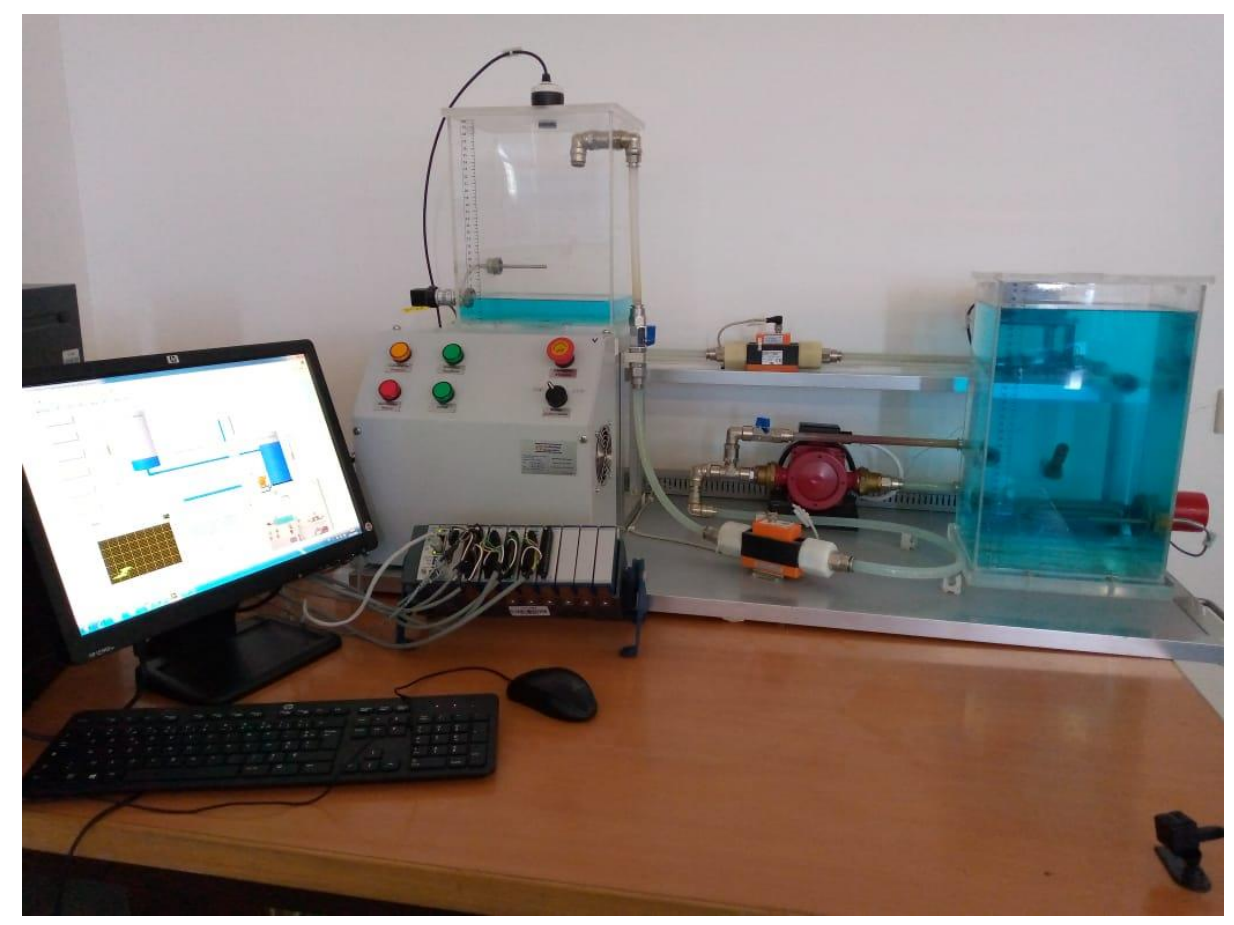

Fig. 6. Requirements for remote laboratory

- Practical works examples

- Acquiring Physical Phenomena

- On/Off Control

- PID Feedback Control

- Lead-Lag Compensation

- Feedback/Feedforward Control

- Multiloop Cascade Control

- Materials' Ratio Control 


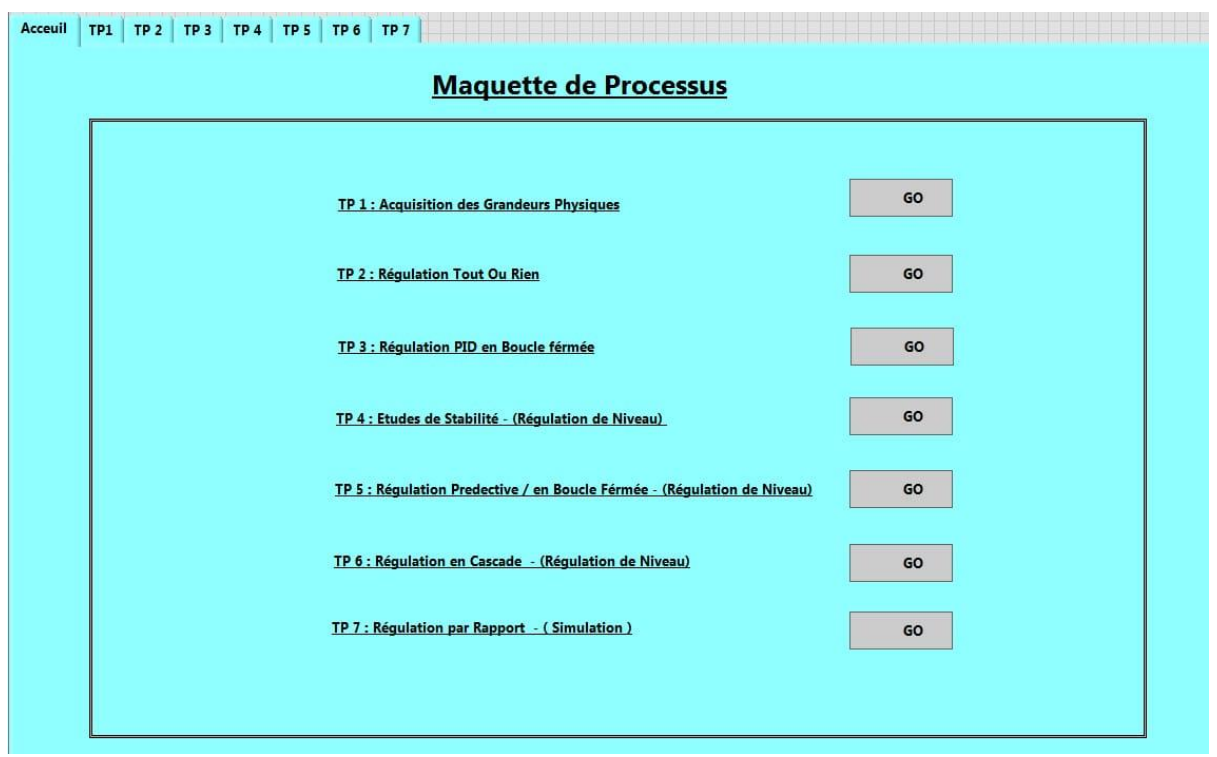

Fig. 7. Interface developed using LabView

\subsection{Process control and measurement}

This practical work is a distance training to understand the measurement and control of processes by level, flow, temperature and pressure as if it is given in real face-toface. It includes all the sensors and actuators needed to perform the full list of experiments for process control and measurement. We have developed an interactive, online LabView interface for the student to gain a better understanding and practical experience of process control.

The curriculum includes learning the principles of acquiring different physical phenomena, On/Off Control, PID control, Feedforward and other types of control used in the industry.

- When the Process Model is running, the Run light on the Control Panel will come on (See Figure 8). 


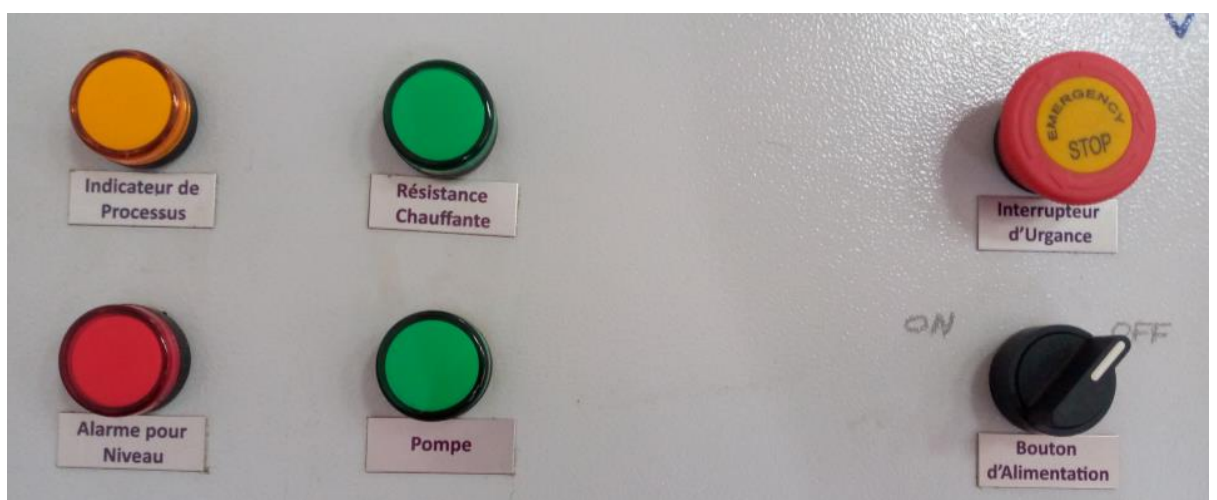

Fig. 8. Indicator Lights on the Control Panel

- When you start the experiment, the Process Indicator Light on the Control Panel comes on.

- When the Pump is running, the Pump Indicator Light on the Control Panel comes on.

- When the Heater is on, the Heater Indicator Light on the Control Panel comes on.

Example labs. We develop this interface to acquire and control all sensors and regulators in the Process Model.

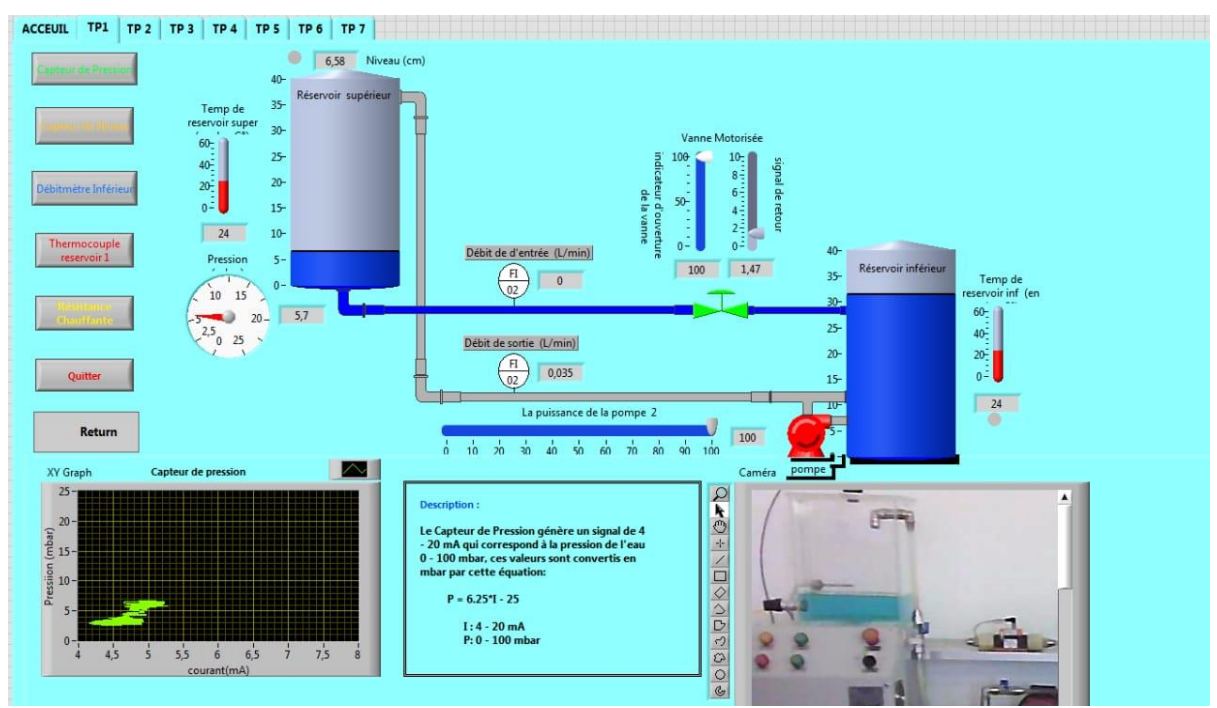

Fig. 9. Acquiring Physical Phenomena (Practical works examples)

First, we start the Process Model, and make sure that the "Run Light" on the Control Panel is on. We make sure that the CompactRIO is connected. Then, we launch the interface in order to accede to the menu of experiments (See Figure 7). For example, 
we click on the Practical Work: Acquiring Physical Phenomena. So, we used the software interface to acquire and control all sensors and controllers in this model.

The sensors and the controllers can be accessed by clicking on their buttons or images in the interface shown in Figure 9, for example, the Flow Meter Button or the Flow Meter image. Therefore, we can see the relationship between Current, Voltage, and the measured value for any sensor.

\section{$5 \quad$ Conclusion and discussion}

We have set up an interactive platform of mutualization between the establishments which consists in the implementation of a set of tools for the comprehension and the simulation of practical works accessible on line for control process monitoring. Therefore, students and trainers and even researchers, in different locations, are able to access a real experiment via the Internet as if they were in the real laboratory. This project was a dream and an ultimate goal for our school, but with this global crisis of COVID-19, it will be a necessity in a more emergency way.

In the following work we will present the proposed methodology to optimize distance learning. We can integrate these Tps/Labs in the current distance learning platforms like other pedagogical activities (courses, exercises, tutorials).

\section{Acknowledgment}

The authors thank the referees very much for their constructive suggestions, helpful comments and fast response, which led to significant improvement of the original manuscript of this paper.

\section{$7 \quad$ References}

[1] E. J. Sintema, "Effect of COVID-19 on the performance of grade 12 students: Implications for STEM education,” Eurasia J. Math. Sci. Technol. Educ., vol. 16, no. 7, pp. 1-6, 2020. https://doi.org/10.29333/ejmste/7893

[2] S. Elfirdoussi, M. Lachgar, H. Kabaili, A. Rochdi, D. Goujdami, and L. El Firdoussi, "Assessing Distance Learning in Higher Education during the COVID-19 Pandemic," Educ. Res. Int., vol. 2020, 2020. https://doi.org/10.1155/2020/8890633

[3] "Moodle - Open-source learning platform | Moodle.org." [Online]. Available: https://moodle.org/. [Accessed: 01-Apr-2021].

[4] "Google Classroom - Applications sur Google Play." [Online]. Available: https://play. google.com/store/apps/details?id=com.google. android.apps.classroom. [Accessed: 01-Apr2021]. https://doi.org/10.7717/peerj.4849/table-6

[5] "Video Conferencing, Meetings, Calling | Microsoft Teams." [Online]. Available: https://www.microsoft.com/en-ww/microsoft-teams/group-chat-software. [Accessed: 01Apr-2021]. https://doi.org/10.1007/978-1-4842-3567-6_1 
[6] D. Louiz, "Enseigner à distance au temps de la Covid-19, cas de la Faculté des Lettres et des Sciences Humaines Ibn Tofail de Kénitra," Didact. Sci. Cogn. Littérature, vol. 4, no. 4, pp. 96-113, 2020. https://doi.org/10.4000/edso.14590

[7] M. Matijević et al., "The development and implementation of a thermal process trainer for control and measurement via the Internet," Comput. Appl. Eng. Educ., vol. 22, no. 1, pp. 167-177, Mar. 2014. https://doi.org/10.1002/cae.20543

[8] C. Hodges, S. Moore, B. Lockee, T. Trust, and A. Bond, "Remote Teaching and Online Learning," Educ. Rev., pp. 1-15, 2020.

[9] A. M. Taj et al., "Conception and Implementation of an IoT System for Remote Practical Works in Open Access University's Electronic Laboratories," Int. J. Online Biomed. Eng., vol. 17, no. 02, pp. 19-36, 2021. https://doi.org/10.3991/ijoe.v17i02.19755

[10] A. Abouhilal, A. M. Taj, N. Taifi, and A. Malaoui, "Embedded Electronics Applied in Remote Laboratories Using NodeJs," Iraqi J. Sience, pp. 1-6, 2021. https://doi.org/10. 24996/ijs.2021.si.1.1

[11] N. Kapilan, "Virtual Laboratory: A Boon to the Mechanical Engineering Education During Covid-19 Pandemic," High. Educ. Futur., pp. 1-16, 2020.

[12] B. G. Andryukov, N. N. Besednova, T. A. Kuznetsova, and L. N. Fedyanina, "LaboratoryBased Resources for COVID-19 Diagnostics: Traditional Tools and Novel Technologies . A Perspective of Personalized Medicine," J. Pers. Med., vol. 11, p. 42, 2021. https://doi.org/ 10.3390/jpm11010042

[13] B. I. Evstatiev and T. Hristova, "Adaptation of Electrical Engineering Education to the COVID-19 Situation : Method and Results“," IEEE 26th Int. Symp. Des. Technol. Electron. Packag., no. October, 2020. https://doi.org/10.1109/siitme50350.2020.9292142

[14] P. M. Hash, "Remote Learning in School Bands During the COVID-19 Shutdown," 2021.

[15] M. P. Kazmierkowski, "Using Remote Labs in Education (Zubia, J.G. and Alves, G.R.; 2011) [Book News]," IEEE Ind. Electron. Mag., vol. 7, no. 1, pp. 67-68, Mar. 2013. https://doi.org/10.1109/mie.2012.2236487

[16] P. Bauer, J. Dudak, D. Maga, and V. Hajek, "Distance practical education for power electronics," Int. J. Eng. Educ., vol. 23, no. 6, pp. 1210-1218, 2007.

[17] Y. Khazri, M. Rouane, A. Fahli, M. Moussetad, A. Khaldouni, and A. Naddami, "Developing a Remote Practice for Laboratory Experiments on Measuring Instruments," Int. J. Online Biomed. Eng., pp. 12-14, 2014. https://doi.org/10.3991/ijoe.v10i5.3833

[18] Y. Khazri, A. Fahli, M. Moussetad, and A. Naddami, "Design and implementation of a reservation system and a new queuing for remote labs," Int. J. online Biomed. Eng., vol. 15, no. 12, pp. 57-68, 2019. https://doi.org/10.3991/ijoe.v15i12.11098

[19] T. Tsiatsos et al., "Evaluation plan and preliminary evaluation of a network of remote labs in the maghrebian countries," Int. J. Interact. Mob. Technol., vol. 10, no. 5, pp. 15-20, 2014.

[20] A. Naddami, A. Fahli, M. Gourmaj, A. Pester, and R. Oros, "Importance of a network of online labs in magrebian countries," Int. J. Interact. Mob. Technol., vol. 10, no. 5, pp. 5-6, 2014. https://doi.org/10.3991/ijoe.v10i5.3795

[21] "Virtual Laboratory." [Online]. Available: https://pages.jh.edu/virtlab/virtlab.html. [Accessed: 26-May-2021].

[22] "Index of / stancil/virtual-lab." [Online]. Available: http://users.ece.cmu.edu/ stancil/ virtual-lab/. [Accessed: 28-May-2021].

[23] "CompactRIO Systems - NI." [Online]. Available: https://www.ni.com/en-lb/shop/ compactrio.html. [Accessed: 05-Jun-2021]. 


\section{Authors}

Hajar Baghdadi is a Ph.D. Student at the Faculty of Technical Sciences (Hassan 1st University, Settat, Morocco). She received her engineering diploma in Electrical Engineering in 2016 from the National School of Applied Sciences of Khouribga. Her main research interest includes Embedded Systems and MEMS Technology.

Mohamed Massour El Aoud received the PhD degree in Automatic from Hasan II Mohammedia Casablanca University, in 2008. From 2008 to 2011, he worked respectively as teacher in different university of Morocco. Since 2011, He has been an Assistant Professor at the Electrical Engineering Department, in the National School of Applied Sciences - Khouribga, Morocco. His area of research includes automatic control and Industrial Engineering.

Ismail Lagrat is professor at the National School of Applied Sciences of Kenitra. Obtained the PhD degree in automatic signals-systems in 2009 and Master of Science and automatic information processing in 2004 from the Faculty of Science Fes city. Research the field of nonlinear control system, robotics and embedded systems.

Karim Rhofir is an Associate Professor at the National School of Applied Sciences in Khouribga (Sultan Moulay Slimane University, Beni-Mellal, Morocco). In 1998, He received his Ph.D in Mathematiques from the University of Besançon, France. Since 2011, he has been working in the field of scientific computing.

Noureddine El barbri is an Associate Professor at the National School of Applied Sciences of Khouribga. He received his Ph.D in physics, Electronics and Artificial Intelligence operation, professor at ENSA in 2008. In 2010, he became an Assistant Professor at the National School for Applied Sciences, Khouribga, Morocco, where he became an Associate Professor in 2015. His research interests include design and realization of multi-sensor systems, electronic nose, data analysis, image processing, artificial vision, artificial intelligence, food processing, electronics of emblematic systems.

Mohamed Lamhamdi is an Associate Professor at the Faculty of Technical Sciences (Hassan 1st University, Settat, Morocco). He received his Ph.D in Materials and Technology of Electronic Components in 2008 from the Paul Sabatier University, Laboratory for Analysis and Architecture of Systems (LAAS), Toulouse, France. From 2008 to 2012, he was a researcher in the LMP STMicroElectronics, Tours. In 2012, he became an Assistant Professor at the National School for Applied Sciences, Khouribga, Morocco, where he became an Associate Professor in 2016. In January 2018, he joined the Faculty of Technical Sciences, Settat, Morocco. His research interests include Material Characterization, MEMS/NEMS Technology, Thin Films and Nanotechnology.

Article submitted 2021-06-10. Resubmitted 2021-07-18. Final acceptance 2021-07-20. Final version published as submitted by the authors. 